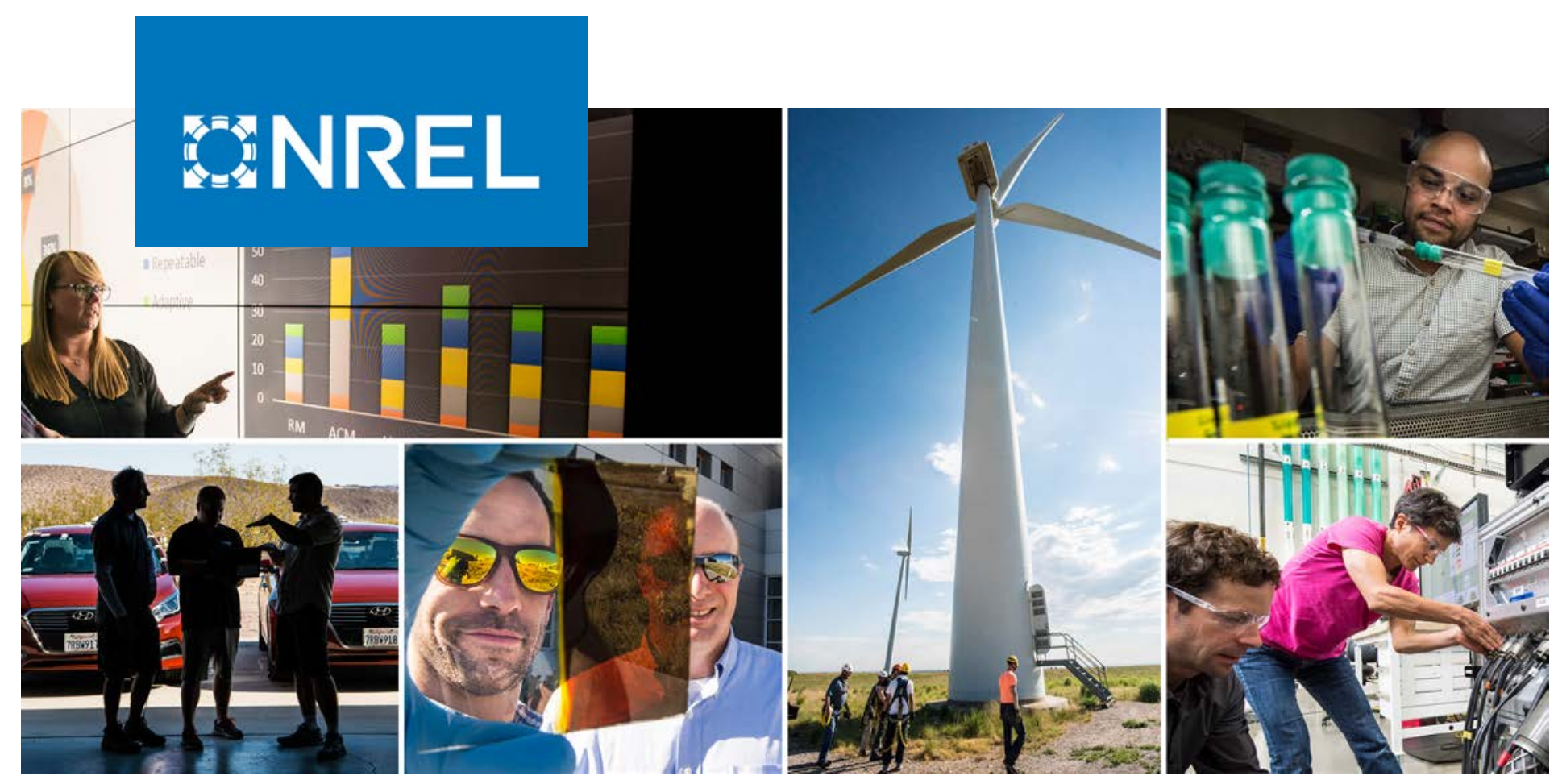

\title{
Networked Microgrid Optimal Design and Operations Tool: Regulatory and Business Environment Study
}

Francisco Flores-Espino, Julieta Giraldez, and Annabelle Pratt

National Renewable Energy Laboratory

NREL is a national laboratory of the U.S. Department of Energy Office of Energy Efficiency \& Renewable Energy

Operated by the Alliance for Sustainable Energy, LLC

This report is available at no cost from the National Renewable Energy Laboratory (NREL) at www.nrel.gov/publications.
Technical Report

NREL/TP-5D00-70944

May 2020 


\section{GNREL}

\section{Networked Microgrid Optimal Design and Operations Tool: Regulatory and Business Environment Study}

Francisco Flores-Espino, Julieta Giraldez, and Annabelle Pratt

National Renewable Energy Laboratory

\section{Suggested Citation}

Flores-Espino, Francisco, Julieta Giraldez, and Annabelle Pratt. 2020. Networked Microgrid Optimal Design and Operations Tool: Regulatory and Business Environment Study. Golden, CO: National Renewable Energy Laboratory. NREL/TP-5D00-70944. https://www.nrel.gov/docs/fy20osti/70944.pdf.

NREL is a national laboratory of the U.S. Department of Energy Office of Energy Efficiency \& Renewable Energy Operated by the Alliance for Sustainable Energy, LLC

This report is available at no cost from the National Renewable Energy Laboratory (NREL) at www.nrel.gov/publications.

Contract No. DE-AC36-08GO28308
Technical Report NREL/TP-5D00-70944 May 2020

National Renewable Energy Laboratory 15013 Denver West Parkway Golden, CO 80401 303-275-3000 • www.nrel.gov 


\section{NOTICE}

This work was authored by the National Renewable Energy Laboratory, operated by Alliance for Sustainable Energy, LLC, for the U.S. Department of Energy (DOE) under Contract No. DE-AC36-08GO28308. Funding provided U.S. Department of Energy Office of Electricity. The views expressed herein do not necessarily represent the views of the DOE or the U.S. Government.

This report is available at no cost from the National Renewable Energy Laboratory (NREL) at www.nrel.gov/publications.

U.S. Department of Energy (DOE) reports produced after 1991 and a growing number of pre-1991 documents are available free via www.OSTI.gov.

Cover Photos by Dennis Schroeder: (clockwise, left to right) NREL 51934, NREL 45897, NREL 42160, NREL 45891, NREL 48097, NREL 46526.

NREL prints on paper that contains recycled content. 


\section{Acknowledgments}

We thank Dan Ton, Paul Wang, and the U.S. Department of Energy, Office of Electricity (OE), for their support of this work. This work was prepared by the National Renewable Energy Laboratory (NREL) with funds from OE. We thank Kevin Schneider at the Pacific Northwest National Laboratory for his team leadership, and we thank Jeff Logan and Santosh Veda from NREL for their review of this work. Finally, we thank the following individuals for their valuable expertise and thoughtful input on networked microgrids: Eric Stein from PECO and Tom Bialek from San Diego Gas \& Electric Company. 


\section{List of Acronyms}

DERMS

DERs

DMS

IEEE

NMG

OD\&O distributed energy resource management system distributed energy resources distribution management system

Institute of Electrical and Electronics Engineers networked microgrid

Optimal Design and Operations (tool) 


\section{Executive Summary}

Microgrids aim to increase the resilience of the electric supply to the loads within the microgrid through the ability to disconnect from the distribution utility in the event of a power outage and by supplying power to the microgrid loads from a combination of multiple power generation assets and storage systems. Microgrids can also improve reliability at the distribution level by reducing the load on the system under stress conditions. Networking two or more microgrids has the potential to increase reliability and resilience at a reduced cost by taking advantage of economies of scale and increasing the diversity of the generation assets and loads.

This report is part of a collaborative effort among several U.S. Department of Energy national laboratories to develop a networked microgrid (NMG) Optimal Design and Operations (OD\&O) tool. This tool addresses the goal defined in the Grid Modernization Multi-Year Program Plan to develop a suite of tools that addresses functional requirements for system optimal design and the operations of NMGs.

The term NMG in this report is defined as two or more microgrids interconnected at the physical layer through the distribution network and at the communications and control layers. NMGs have the potential to reduce installed and operational costs when compared to independent microgrids through economies of scale and by sharing complementary distributed energy resources. By sharing loads and generation resources, NMG systems increase the chance of matching supply and demand of electricity for all loads with internal resources.

This report describes the impact of electric utility regulations in the United States on the feasibility of NMGs, and it presents possible ownership, development, and operational business models for NMGs. The report also identifies the required changes to existing regulatory environments that would allow the implementation of NMGs. Although the rest of the multilaboratory effort will concentrate on the technical aspects of developing the OD\&O, the regulatory part of the study will focus on the conditions that need to occur to enable the deployment of NMG systems in the United States.

Most states in the United States do not have regulations that apply specifically to microgrids, yet regulation can greatly affect the economic viability of microgrids. The lack of microgrid-specific regulation hinders microgrid development and creates a situation in which each microgrid could face different regulatory constraints depending on its unique configuration. A handful of statessuch as New York, New Jersey, Connecticut, and California-have started efforts to implement microgrid development and operation regulations; however, even the most rudimentary microgrid-specific regulation on NMGs is lacking in the rest of the country.

Although there is much variability among existing regulatory environments, they fit one of three categories: traditional, partly deregulated, or fully deregulated. This report describes how these regulatory environments can affect microgrid economic performance. We also consider a fourth, hypothetical, NMG-friendly environment. The objective is to use the qualities of these regulatory environments to appropriately structure the OD\&O tool to design and assess the benefits of

NMGs. Although the first three regulatory environments can be found in different jurisdictions in the United States, the NMG-friendly environment does not exist today, and it would have the least amount of constraints on the operation of NMGs. It will require regulators to incentivize or 
mandate utilities to allow NMGs to energize utility-owned infrastructure during an outage. It will also require advances in distribution management system and distributed energy resource management system technologies to enable feeder sections containing NMGs to be isolated.

As a follow-on step, creating a set of use cases with NMGs that use the ownership models and regulatory environments described in this report could increase our understanding of the impact of regulatory environments and ownership models on the benefits of NMG systems. 


\section{Table of Contents}

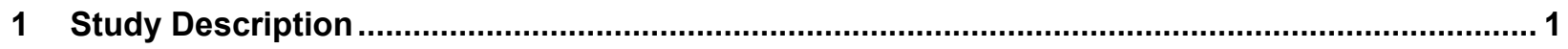

2 Electric Utility Regulatory Environment.............................................................................. 4

2.1 Current Utility Regulation.........................................................................................

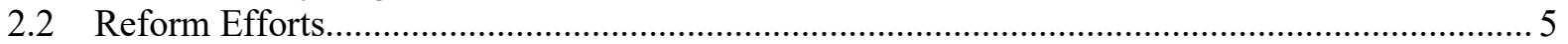

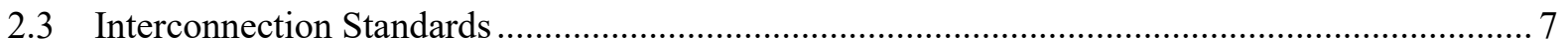

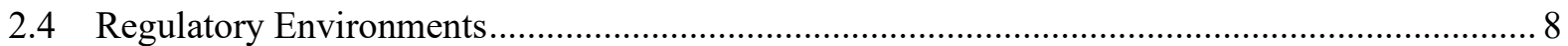

3 Networked Microgrids Business Models ......................................................................... 12

3.1 Ownership Types............................................................................................... 12

3.1.1 Utility 100\%: Vertically Integrated Utility Microgrids......................................... 12

3.1.2 Mixed: The Utility Owns the Microgrid's Network Infrastructure and the Utility and Users Own Distributed Energy Resource Assets ................................................. 13

3.1.3 Unbundled: The Utility Owns the Network Infrastructure and the Users Own Distributed Energy Resource Assets ............................................................... 13

3.1.4 User 100\%: The Users of the Microgrid Own Distributed Energy Resource Assets and

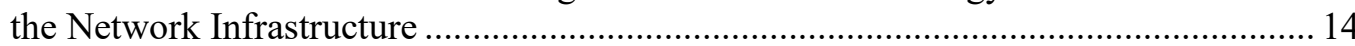

3.2 Ownership Types and the Regulatory Environment .................................................. 14

4 Conclusions and Future Work ........................................................................................... 15

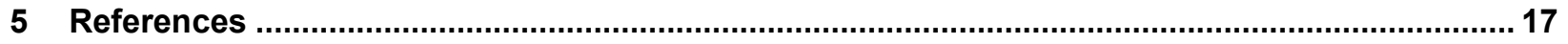




\section{List of Figures}

Figure 1. The business model of a microgrid is designed to fit within the intersection of regulations and

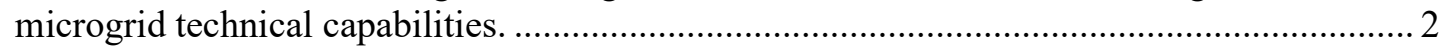

Figure 2. Simplified diagram of two networked microgrids interconnected to the same feeder ............... 10

Figure 3. Business models are the result of the intersection between the enabling aspects and constraints of the regulatory environment and the capabilities of the microgrid. 16

\section{List of Tables}

Table 1. System Attributes for the Proposed City of Syracuse Microgrid.............................................. 16 


\section{Study Description}

An electric system is most vulnerable at the distribution level. More than $90 \%$ of electric power interruptions originate at the distribution level (U.S. Department of Energy 2017). Utilities, developers, consumers, and the government are showing more interest in microgrids to increase the resilience, security, and reliability of electricity supply. A microgrid is defined as a "group of interconnected loads and distributed energy resources (DERs) with clearly defined electrical boundaries that acts as a single controllable entity with respect to the grid and can connect and disconnect from the grid to enable it to operate in both grid-connected or island modes" (Ton and Smith 2012). Microgrids can improve resilience and reliability through their ability to disconnect from the distribution grid during an outage and provide power to loads within the microgrids' boundaries. In a 2017 Harvard Business Review study, business, hospital, and higher education leaders revealed strong concerns about rising energy costs and business interruptions from weather-related events. The study shows that one-third of the organizations surveyed generate their own power to reduce energy costs and increase operational resilience (Harvard Business Review Analytic Services 2017). Further, coordinating the design and operation of two or more microgrids takes advantage of economies of scale and geographic and load diversity, and could help make distribution networks even more resilient at a reduced cost and increased efficiency (Barnes et al. 2017).

NMGs can be connected via primary or secondary voltage conductors that are utility or privately owned. Under normal conditions, the microgrids are networked through the distribution grid. Under abnormal conditions, such as physical damage to the distribution grid that results in an outage, they can either operate independently or become networked after the closing of one or more switches.

Further, although "independent local controllers may manage the microgrids, another controller that has some visibility into each of the networked microgrids coordinates the objectives and operations of these independent controllers at a higher level" (Backhaus et al. 2016).

A consortium of U.S. Department of Energy national laboratories is developing an Optimal Design and Operations (OD\&O) tool for networked microgrids (NMGs) ${ }^{1}$. This tool development effort addresses the goal defined in the Grid Modernization Multi-Year Program Plan ${ }^{2}$ to develop a suite of tools that addresses functional requirements for optimal system design and operations of NMGs. The present document is part of that collaboration and aims to clarify the enabling and constraining aspects of the regulatory and business environments in the United States and identify the space in which the capabilities of NMGs can be fully deployed according to the rules of a given regulatory environment.

Each jurisdiction, such as a state or municipality, has a set of regulations that we refer to as the regulatory environment. Microgrid developers might find that some of the regulations in a specific environment positively affect the development of microgrids in general, or some specific

\footnotetext{
${ }^{1}$ The GitHub page for the OD\&D tool is located at https://github.com/lanl-ansi/ODO.

2 The Grid Modernization Multi-Year Program Plan is available at https:/energy.gov/sites/prod/files/2016/01/f28/Grid\%20Modernization\%20Multi-Year\%20Program\%20Plan.pdf.
} 
aspects of microgrid design, by lowering microgrid development costs, by allowing or even rewarding the use of some of the features of microgrids, or by other means. We call these regulations enabling regulations. Alternatively, developers might find that other regulations hinder microgrid development by making it more expensive to develop microgrids or by precluding the use of some features. In Figure 1, the enabling aspects and constraints of a given regulatory environment are represented as a black circle. The orange circle represents the technological and operational capabilities of an NMG system. The intersection between these two circles represents the range of possible ownership and operational business models that the owners can choose from. This report does not consider any limitations in microgrid capabilities and therefore focuses on analyzing the enabling aspects and constraints of current regulatory environments (i.e., the range of possible black circles) and the possible ownership and business models that exist within each regulatory environment.

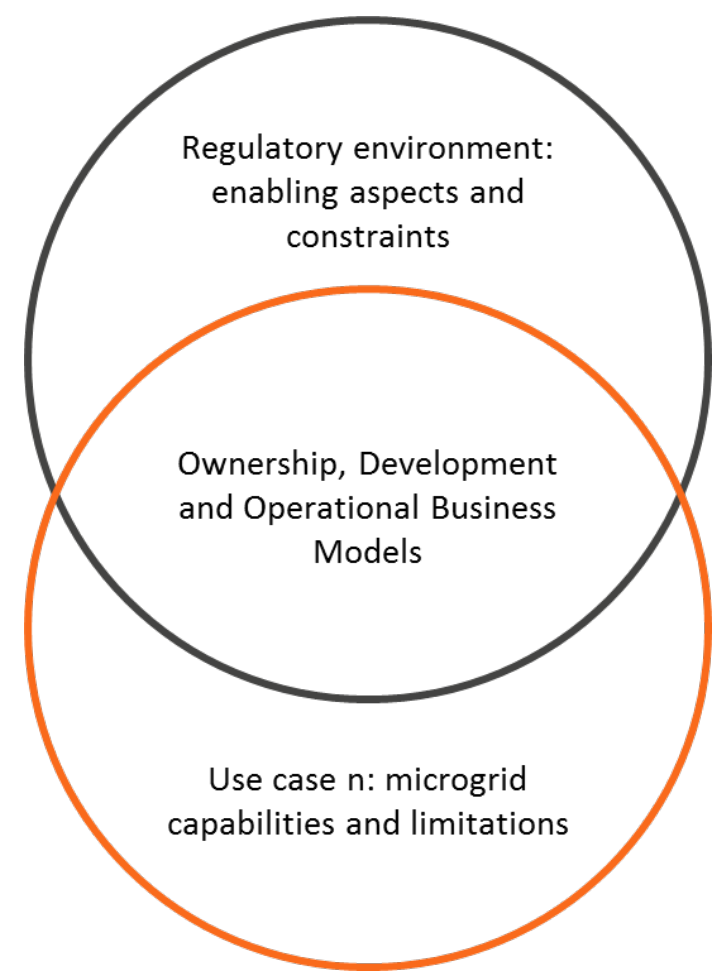

Figure 1. The business model of a microgrid is designed to fit within the intersection of regulations and microgrid technical capabilities.

This report also identifies the required changes to existing regulatory environments that would allow the implementation of NMGs. The report centers on state-level regulatory environments because state legislatures and public utility commissions define and enforce franchise rights, utility regulations, and other policies that significantly influence microgrid business model structure and, hence, microgrid economic performance.

Section 2 describes the current regulatory situation for microgrids, including constraints and initiatives as well as four hypothetical regulatory environments that reflect the regulations found in three types of jurisdictions in the United States and a fourth environment that is hypothetical but has the least amount of constraints to the operation of NMGs. Section 3 describes possible 
business models for NMGs and discusses their viability within different regulatory environments. Section 4 describes the next steps in this study. 


\section{Electric Utility Regulatory Environment}

Most states in the United States do not have regulations that specifically address microgrids even though regulation can greatly affect the economic viability of microgrids. This lack of guidance is because historically only the incumbent utility has been allowed to generate electricity and serve customers in each territory since the inception of electric utilities operating as regulated monopolies. The rationale was to lower electricity costs by removing the incentive for competitors to build duplicative infrastructure. The lack of microgrid-specific regulation creates a situation in which each microgrid faces different regulatory constraints depending on its unique configuration. Only a handful of states - such as New York, New Jersey, Connecticut, and California - have started efforts to implement microgrid development and operation regulations (Eisenstat, Lehfeldt, and Jeschke 2016; Siemens 2015; Stanton and Zimmer 2018).

\subsection{Current Utility Regulation}

The lack of regulations that clarify the rights and responsibilities of microgrid owners as a class hinders microgrid development. Compounding the effect of this void is the regulation of utilities as natural monopolies in many jurisdictions. Utility franchise agreements allow utilities to cross public rights-of-way, and they grant exclusive monopoly to the incumbent utility over electricity sales and distribution infrastructure (Bronin and McCary 2013). Franchise agreements limit the ability of private microgrid owners to provide energy to third-party loads ${ }^{3}$ without becoming a regulated utility, particularly when servicing these loads requires infrastructure that crosses public property (Erickson 2016; Electric Power Research Institute and Smart Electric Power Alliance 2016). The utility, as the sole provider of electricity, has an important influence on the profitability and operation of microgrids: on one hand, they set the retail rates and tariffs (with PUC approval) for DERs that directly affect the return on investment of DER projects; on the other hand, they own and operate the distribution infrastructure that might require costly upgrades to enable NMGs to interconnect during an outage. Utilities also have a role to ensure that generation projects that interconnect to the grid comply with safety and reliability standards; however, in a 2014 survey, $47 \%$ of utility executives interviewed considered that microgrids could erode utility load, which might create a conflict of interest (Utility Dive 2014).

Local and state regulations might prohibit microgrids from serving third-party or offsite loads; other states limit the number of customers the microgrid serves or the service radius. For example, Iowa sets the limit at five customers, and Minnesota at 25 (Siemens 2015; Walsh 2014). Microgrids that serve third-party loads or build infrastructure that crosses public property (e.g., a public street) run the risk of being subject to public utility regulation. Utility regulation might require reliability standards that could be burdensome for a microgrid, give the public utility commission control over financial operations in some states (e.g., New York), or impose other barriers to implementation (Saadeh 2015; Siemens 2015). Serving offsite loads can also mean higher permitting costs.

\footnotetext{
${ }^{3}$ In general, third-party loads mean loads not owned by the private generator or microgrid owner (or the local utility). In some states, generators are allowed to serve on-site loads owned by others without needing to become a utility.
} 
Technology that cost-effectively allows for peer-to-peer energy transactions exists today; however, regulations do not allow energy trading — physical or virtual — without any utility involvement yet (Mengelkamp et al. 2017; Lott 2015; Cardwell 2017; Deign 2019).

Community Choice Aggregation is a program available within the service areas of investorowned utilities in California that allows cities and counties to buy or generate electricity for residents and businesses within their territories (Pacific Gas and Electric n.d.). The Community Choice Aggregation program can be advantageous to microgrids formed under the Community Choice Aggregation regime because it would allow them to (1) not be subject to regulation as electric corporations, (2) use the utility's infrastructure to transmit electricity, and (3) develop subrates that apply to their customers (Erickson 2016). However, the fact that utility-owned distribution system infrastructure would need to be energized to power customers during an outage would still require the involvement of the distribution system operator to upgrade and operate its infrastructure during an islanded mode of operation.

\subsection{Reform Efforts}

Defining microgrids legislatively or regulatorily helps delineate the attributions and responsibilities of microgrid owners in a way that avoids the ambiguity of relying on alternative concepts that might not fully capture the features that set microgrids apart from other forms of DERs, and it can establish the limits of local utility franchise agreements (Grimley and Farrell 2016).

Connecticut reformed its laws to define microgrids as "group of interconnected electricity users and generators that (1) is within clearly defined electrical boundaries that acts as a single controllable entity in respect to the larger electrical grid and (2) can operate as either a part of the larger grid or independent of it, in "island mode" (Hansen 2012). ${ }^{4}$ Connecticut case law establishes that franchise agreements are not exclusive, which means that the legislature can enable microgrid sponsors to cross public rights-of-way, such as streets. In 2013, Connecticut's legislature granted municipal microgrids the right to cross public rights-of-way (Bronin and McCary 2013; Connecticut Department of Energy and Environmental Protection 2018). The Connecticut reform suggests that a regulatory environment that is friendlier to NMGs could emerge from these efforts to reform existing regulatory settings.

The New Jersey Board of Public Utilities has proposed a classification of microgrids based on the number of DERs and interconnection to the grid: 1) one meter and one DER, 2) one meter and one or more DERs, and 3) multiple meters and one or more DERs. However, the report clarifies that such classification does not address the issue of the regulatory status of microgrids as public utilities (New Jersey Board of Public Utilities 2016; National Electrical Manufacturers Association 2018). New Jersey has provided funding to support community microgrids feasibility studies and training programs (Wood 2017a; Community Microgrids Planning Academy 2020).

\footnotetext{
${ }^{4}$ The U.S. Department of Energy Microgrid Exchange Group microgrid definition is essentially the same (Ton and Smith 2012), and it might have been the source for Connecticut's definition.
} 
More recently, legislators in several states have enacted legislation to support grid modernization and activities that support microgrid development. In Hawaii, lawmakers authorized the National Energy Laboratory of Hawaii to build a microgrid demonstration project and directed the Public Utilities Commission to develop a microgrid services tariff (Proudlove et al. 2019). In Kansas, lawmakers passed a bill requiring a study of grid modernization options, including microgrids (Proudlove, Lips, and Sarkisian 2019).

Legislators in Michigan, New Jersey and Pennsylvania introduced bills that supported microgrid development in different ways, including a statutory definition in Michigan, but these bills did not pass (Proudlove et al. 2019).

State regulators have also seen pilot utility projects as a means to explore the potential benefits of microgrids. One example is Commonwealth Edison's Bronzeville microgrid project, which was approved by the Illinois Commerce Commission in March 2018. The Bronzeville microgrid will integrate with the Illinois Institute of Technology's existing microgrid. The commission sees the project as a learning opportunity to "evaluate other opportunities to implement advanced distribution system technology, including microgrids." The approval includes a provision requiring the utility to allow third parties to interconnect microgrids to the utility's infrastructure. The utility will be involved in the design, implementation, and operation of third-party microgrids to ensure that the microgrids provide services that support the reliability of the grid and island properly during outages (St. John 2018; Wood 2018). In Oregon, regulators opened a proceeding on distribution system planning in 2019 to develop a transparent and robust planning process at the distribution level, including microgrids as part of the future distribution system (Proudlove et al. 2019).

Some states have also implemented grant programs to promote microgrids. The NY Prize offered grants to complete 83 feasibility studies across the state and to pay for the design of 11 microgrids selected from the 83 studies. In a future phase, the NY Prize will offer grants to build a selection of the 11 microgrid designs (New York State Energy Research and Development Authority 2020). California and Connecticut have offered grants to microgrids as well.

Reforming utility regulations to decouple energy sales from revenue can help diminish the potential conflict of interest of utilities having the authority to deny interconnection to microgrids. New York's Reforming the Energy Vision is a comprehensive effort to reform energy regulation in the state with the goal of building a clean, more resilient, and affordable energy system (New York State n.d.).

Reforming the Energy Vision aims to convert regulated utilities into wires-only distribution system platform providers to align utility revenues with the goals of the program and eventually decouple revenues from energy sales (New York State n.d.; Bade 2016). This approach has other advantages for microgrid development because distribution system platform providers are also responsible for coordinating scheduling and dispatching at the distribution level and for compensating DERs for additional products and services (California Energy Commission, California Independent System Operator, and California Public Utilities Commission 2017).

Regulatory reforms that address the unique capabilities of microgrids are ongoing in a few jurisdictions; however, NMGs do not seem to be a subject that regulators in any jurisdiction are 
addressing. Some jurisdictions could be friendlier to NMG development today because of the flexibility of their franchise agreements and their efforts to introduce microgrid-specific regulations (e.g., Connecticut), but in general existing regulations greatly limit the deployment of economically sustainable NMGs across the country.

In most cases, each microgrid in an NMG system would serve loads owned by other entities and would have to cross public rights-of-way to exchange energy with its partner microgrid(s). A microgrid that serves the loads of other owners or crosses public rights-of-way might violate the incumbent utility's franchise to be the sole provider of electricity in a certain territory. Whether a microgrid encroaches on existing utility franchise agreements depends on the terms of the local utility's franchise, on whether the microgrid is considered - or chooses to be considered-a public utility, and on other factors. Franchise rules also dictate whether a microgrid owner can sell electricity and install facilities in public streets. Even though being regulated as a utility might grant a microgrid these franchise benefits, it also has important implications regarding the microgrid's exposure to economic regulation by utility commissions.

In our regulatory survey, we didn't find any environment that would support the full economic, resilience, and technical benefits that the coordinated operation of two or more microgrids could bring about. This situation is not unlike what existed at the beginning of single microgrid development and deployment; however, the lack of regulatory guidance did not impede advancements of this enabling technology. The limitations of existing regulatory environments led us to consider a regulatory environment that currently does not exist in our exploration of hypothetical regulatory environments (Section 2.4), the first three of which are based on the regulations of actual jurisdictions. Such an environment, which we're calling the NMG-friendly environment, will help us explore the benefits of NMGs unconstrained by current regulatory barriers.

\subsection{Interconnection Standards}

Many utilities refer to the interconnection standard IEEE 1547 (Standard for Interconnecting Distributed Resources with Electric Power Systems) in their interconnection agreements. Standards such as IEEE 1547 provide guidance on utility voltage and voltage-regulating equipment, overcurrent protection, effective grounding, islanding prevention, harmonics, voltage flicker, telemetry and metering equipment, among other issues. The IEEE 1547-2018 standard (Standard for Interconnection and Interoperability of Distributed Energy Resources with Associated Electric Power Systems Interfaces) includes requirements for energizing the distribution grid for intentional islands (or microgrids), as well as interoperability requirements between the local DER and the utility or DER managing entity. ${ }^{5}$ While these interconnection standards inform the interconnection process for microgrids, oftentimes the interconnection process is executed separately for each DER in the microgrid, as opposed to considering an interconnection process for the microgrid as a system. The main reason for this is that the financial compensation mechanism is not the same for every DER resource. Identifying a

${ }^{5}$ A DER Managing Entity is defined in IEEE 1547-2018 as "an entity that monitors and manages the DER through the local DER communication interface. The DER managing entity could be for example a utility, an aggregator, a building energy management system, or other." 
microgrid as a single system for interconnection purposes is still the exception and there is not a standardized process.

Additionally, IEEE 1547.4-2011 (Guide for Design, Operation, and Integration of Distributed Resource Island Systems with Electric Power Systems) provides guidance on good practices for microgrid design, operations, and integration with the grid. It addresses both islanded and gridconnected operation. This guide standardizes technical language for microgrids, and it describes important considerations when designing islanded power systems (microgrids) with DERs; however, it does not address testing and interconnection rules for such systems.

IEEE 2030.7-2017 (IEEE Standard for the Specification of Microgrid Controllers) covers the core functions of microgrid controllers that are common to all microgrids. The standard also links the functional specifications with testing procedures. IEEE 2030.8-2018 (IEEE Standard for the Testing of Microgrid Controllers) establishes standardized microgrid controller testing procedures that allow for component and control algorithm flexibility and customization while ensuring that minimum requirements are met. These standards are intended to (1) address the technical issues and challenges of microgrid controller operation that are common to all microgrids and to (2) present the control approaches required from the distribution system operator and microgrid operator (EPRI and SEPA 2016; Joos et al. 2017).

\subsection{Regulatory Environments}

The regulatory environment sets ownership and operational constraints. We considered four regulatory environments with different levels of microgrid regulatory stringency. The objective is to use the key qualities of these regulatory environments to appropriately structure the OD\&O tool for NMGs to reflect the design constraints in each environment. This will enable our team to evaluate the benefits of networking two or more microgrids while facing different levels of the regulatory constraints, as described in Section 2.1. Three of the following environments are based on regulations from actual jurisdictions. We also include a fourth hypothetical environment, which is not based on an actual jurisdiction; instead, this environment represents a collection of the regulations that are most favorable to the concept of NMGs.

Attributes that all our hypothetical environments (as well as all the jurisdictions reviewed) have in common is that the distribution grid is the property of the incumbent distribution utility and the responsibility of ensuring safe and reliable operation falls on this entity.

Regulatory environments considered in this report include:

1. Traditional: utilities regulated as monopolies

This environment is based on jurisdictions with vertically integrated utilities regulated as monopolies, such as Colorado. In the traditional environment, utilities are not explicitly barred from owning and operating DERs. Utilities are generally the only entities allowed to own and operate power generators and distribution lines with a few exceptions, such as customers generating their own power on-site or third-party entities generating power for on-site consumption.

2. Partially deregulated: utilities regulated as (mostly) wires-only monopolies 
This environment is based on the regulatory environment in California. In this environment, utilities underwent a partial deregulation and divested themselves of most of their generation assets; however, utilities are not explicitly barred from owning generation assets, although they do require explicit permission from the regulators.

3. Deregulated: utilities regulated as distribution system operators

The third environment considered has undergone a complete process of deregulation, understood as the mechanism that made utilities divest all their generation assets. In this environment — based on New York and Texas - utilities are explicitly barred from owning generation except in cases where the utilities can make the case that generation improves access to electricity by disadvantaged sectors of society, improves reliability, or as part of pilot projects that would help regulators understand new technologies.

4. NMG-friendly

The most salient feature of the NMG-friendly environment is that microgrids can freely exchange energy and other services during normal operations and during outages. This environment allows peer-to-peer transactions so that users in more than one microgrid can invest in the assets and share the revenue of the investment in two or more microgrids. If the microgrids are connected by a utility-owned conductor, the operator of the NMGs and the local utility would agree on the conditions that will allow the NMG operator to use and possibly operate the utility's infrastructure. This agreement would prevent any conflicts between the utility and microgrid operator when the interests of both parties collide - for example, when the utility wants to reconfigure the network for reliability reasons in a way that might affect the microgrid owner's profitability. Additionally, the interests of the utility's customers that could be potentially affected during network reconfigurations could be protected in the agreement. The networking of microgrids connected by a privately-owned conductor is also allowed within this environment.

For microgrids connected by a utility-owned conductor to operate in a networked configuration under emergency operating conditions, the section of the distribution grid that the NMGs will energize needs to be isolated from the rest of the utility network. To accomplish this, NMGs can reconfigure network topology and dispatch generation and control load without intervention from the utility or have utility involvement to modify the network topology and then dispatch generation and control load. If NMGs can control the network topology, they must always transparently communicate the status of the network to the utility, and the NMGs need to be allowed to energize that section of the grid (utility-owned infrastructure). The loads on this grid section can be either disconnected or considered part of the NMG design. This is illustrated in Figure 2. 


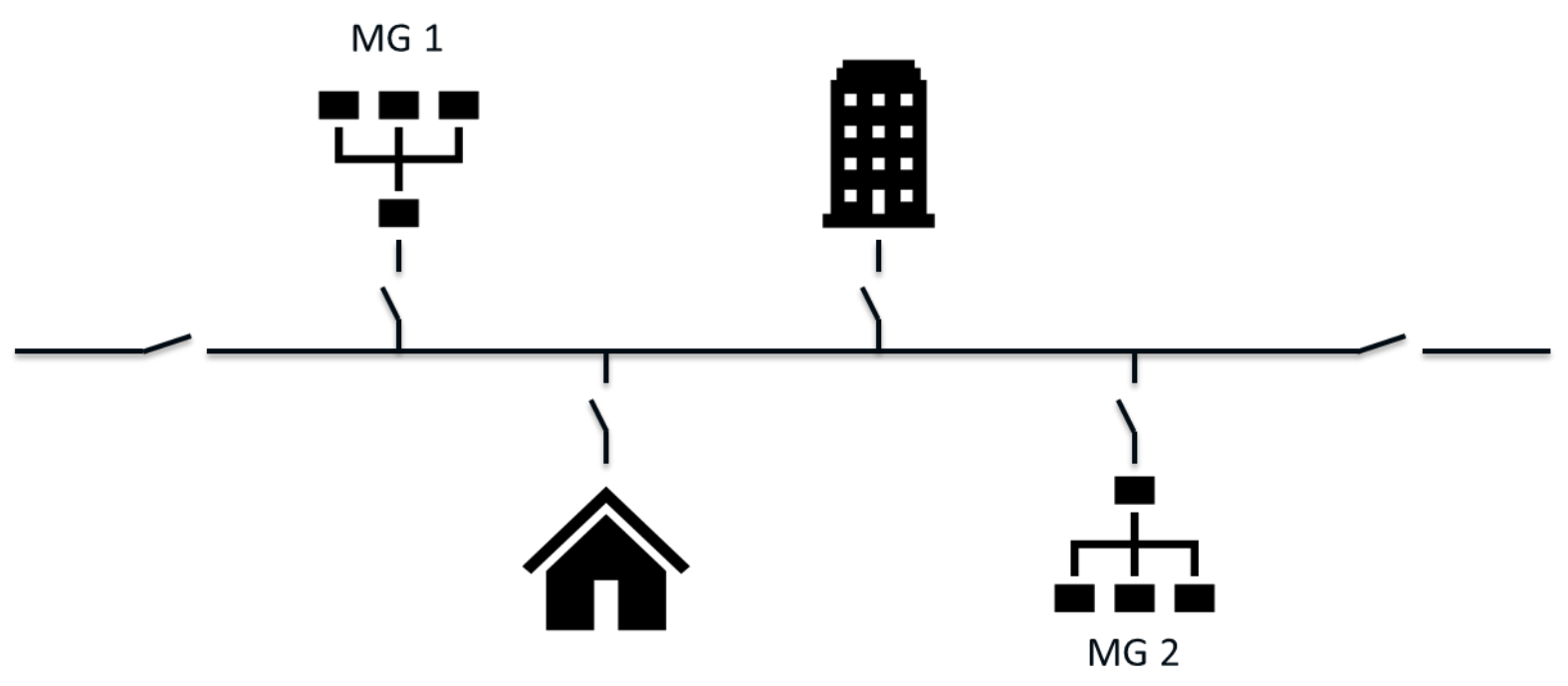

Figure 2. Simplified diagram of two networked microgrids interconnected to the same feeder

This environment does not exist today in any jurisdiction in the United States. It is considered in this report to allow us to model NMGs that can fully deploy all their capabilities and for the OD\&O tool for NMGs to explore the benefits of linking the operation of microgrids compared to the individual operation of separate microgrids.

This unique environment will require regulators to incentivize or mandate utilities to allow NMGs to energize utility-owned infrastructure during an outage. The energized infrastructure in the models used by the OD\&O tool will be limited to using the distribution system only. This means that if the microgrids are served by different substations under normal conditions, the subtransmission network will not be energized to network them during an outage.

An NMG-friendly environment also requires advances in distribution management system (DMS) and distributed energy resource management system (DERMS) technologies to enable a platform for communications between microgrid controllers and the utility and to perform network topology changes for feeder sections containing NMGs to be isolated. Currently, DMS platforms have limited visibility of the DERs and microgrids interconnected to the distribution system, and DERMS platforms are not fully integrated into distribution real-time operations (Wang, Chen, and Lu 2015). The U.S. Department of Energy is addressing these shortcomings and has sponsored an evaluation of the potential to integrate measurement and control technologies for DERs, microgrid controllers, and DERMS with DMS (Argonne National Laboratory et al. 2017).

From a technical perspective, safely energizing a portion of a primary distribution feeder for two microgrids to network would require upgrades to the utility-owned infrastructure. The protection scheme for a two-way power flow on the primary feeder would require state-of-the art protection equipment with two-way power flow detection methods featuring adaptive and/or communications-assisted protection schemes and appropriate fault detection in islanded mode. Defining a limited and predefined set of configurations by which microgrids can be networked will reduce the impact on utility-owned infrastructure. 
Finally, realization of an NMG-friendly environment might require updates to relevant interconnection standards, such as IEEE 1547, to address considerations for more than one microgrid energizing the grid (or portions thereof) to interconnect with each other during an outage. 


\section{Networked Microgrids Business Models}

This section describes different ownership types for network infrastructure and DERs within NMGs, in contrast to the previous section, which focused on regulatory environments. We also include a discussion on how regulations could create conditions that are more conducive to some ownership types than others.

\subsection{Ownership Types}

Regulations in the United States allow, in general, significant flexibility by offering different types of ownership. In the case of NMGs, we identified four main types of ownership:

- Utility $100 \%$

- Mixed

- Unbundled

- User $100 \%$.

Because utility franchise agreements and other regulations limit who can sell electricity in each territory, each ownership type is limited in a different way by the regulatory environment.

In describing the different ownership types, we use the term user to refer to entities that receive some of their power from the DERs owned by the microgrid. The ownership types described next apply to single microgrids as well as to NMGs. Given that an NMG is a relatively new concept, there are not many examples of NMGs operating today. Therefore, we used single microgrid projects as examples for this section.

\subsubsection{Utility 100\%: Vertically Integrated Utility Microgrids}

Microgrids that are $100 \%$ utility-owned are not limited by franchise agreements and can use the utility's existing distribution infrastructure, which in general gives this type of microgrid or NMG ample operational flexibility; however, public utility commissions and the DER industry have voiced concerns about utilities entering the DER market (regardless of whether that would involve microgrids or not) because of the competitive advantages that a utility might have in deploying distributed systems within their territory, including low financing costs, a large preexisting customer base, and a regulated way to recoup investments (Girouard 2017). This question has not been settled mainly because to date very few utilities have sought to deploy DER technology (Pyper 2016). Some utilities see microgrids as a way to provide more reliable service to certain customers, and they have expressed interest in developing microgrids, even if regulators only approve recovering the capital for this type of investment without any return. ${ }^{6}$

This type of ownership might face other regulatory barriers. Traditionally, regulators in several jurisdictions have not approved the idea of utilities owning assets on the customer side of the meter (California Public Utilities Commission 2014). In some deregulated states, such as the State of New York, utilities are expressly barred from owning DERs except for reliability purposes, to boost service in underserved markets, or to demonstrate projects that feature innovative business models (Girouard 2017); however, in some jurisdictions utilities might

\footnotetext{
${ }^{6}$ Personal communication with Eric Stein, principal engineer at PECO.
} 
receive permission from regulators to own generation assets in the distribution network. In Arizona, for example, two pilot projects have been approved by the state's public utilities commission to own rooftop solar systems within customers' premises (Bade 2015). Legislators in Pennsylvania introduced a bill in 2017 that would allow public utilities to invest in microgrids, including generation and energy storage assets, to boost reliability, especially during disasters. The bill would allow public utilities to recover microgrid costs in customer rates. The legislature sent the bill back to committee, where it remains as of May 2020 (Wood 2017b; Walton 2017; Pennsylvania General Assembly 2018).

Oncor, a utility in Texas, owns and operates a microgrid built in the town of Lancaster, Texas. The microgrid integrates energy storage, photovoltaic generation, a propane microturbine, and legacy fossil-fueled generation with the goal of boosting grid capacity and reliability. The microgrid has four segments that can operate independently of each other and island from the grid if there is an outage (Pyper 2015; Schneider Electric 2016).

\subsubsection{Mixed: The Utility Owns the Microgrid's Network Infrastructure and the Utility and Users Own Distributed Energy Resource Assets}

Mixed ownership microgrids combine generation and other DER assets owned by the utility and those owned by the microgrid users. The utility owns the microgrid's network infrastructure, which might be part of the distribution network. The mixed ownership type is allowed only in jurisdictions where utilities can own generation assets, similar to the utility $100 \%$ ownership type.

San Diego Gas and Electric owns the distribution grid and most of the large-scale power generation assets of the Borrego Springs microgrid demonstration project. This microgrid also includes a large photovoltaic plant owned by Clearway Energy, and it integrates customer-owned photovoltaic systems and other DER assets, such as remotely-controlled residential thermostats (California Public Utilities Commission 2014; New York State Energy Research and Development Authority 2010; Bialek 2014).

\subsubsection{Unbundled: The Utility Owns the Network Infrastructure and the Users Own Distributed Energy Resource Assets}

In the unbundled ownership model, the utility does not own any DER assets. This ownership type is suitable for jurisdictions in which the utility owns and manages the distribution network but is barred from owning generation assets.

In New York, the City of Syracuse applied for a NY Prize grant (see Section 2.2) proposing an unbundled microgrid that would be operated by the local utility, National Grid, and the owner of the largest generator in the microgrid, the Onondaga County Resource Recovery Agency. The microgrid will serve more than 2,000 users distributed across 18 government, public, commercial, and residential loads. The microgrid will feature a 39.6-MW waste-to-energy generation facility owned by Onondaga County Resource Recovery Agency and a 2-MW combined heat and power system owned by the Upstate University Hospital Community Campus. The microgrid will not have exclusive network infrastructure; it will use the local distribution network owned by National Grid. The proposal was awarded funding for a feasibility study in the first phase of the NY Prize, and funding to complete the design in Phase II. 


\subsubsection{User 100\%: The Users of the Microgrid Own Distributed Energy Resource Assets and the Network Infrastructure}

In this ownership model, microgrid users own all microgrid assets, which include the power lines and DER assets. Campus microgrids are the most common example of this ownership type. In a campus microgrid, a large institution or consortium of institutions (for example, a university or several close-by hospitals) interconnect their loads and DER assets through a network of power lines to increase reliability, lower costs, or add clean generation.

The Burrstone Energy Center in Utica, New York, is owned and operated by an ad hoc company to serve the electric and thermal loads of a college campus, a clinic, and a nursing home (COGEN Power Technologies n.d.). The Santa Rita Jail microgrid in Dublin, California, integrates storage, photovoltaic, and diesel generation technologies to reduce energy consumption on-site and to provide energy during outages (KEMA and Massachusetts Clean Energy Center 2014; Lawrence Berkeley National Laboratory n.d.).

\subsection{Ownership Types and the Regulatory Environment}

Each regulatory environment presents different constraints to each ownership type, generally making one ownership type more costly or difficult. If everything else is equal, for example, it might be more difficult to build a utility $100 \%$ microgrid or NMG in states such as New York or Texas, where utilities are generally not allowed to own generation assets; however, a business type would rarely be completely proscribed in a specific regulatory environment. In New York, under the Reforming the Energy Vision order, utilities might apply for waivers to the restriction to own DER assets. In Texas, where transmission and generation utilities are barred from owning DERs, Oncor's Lancaster microgrid is $100 \%$ utility-owned.

The constraints that regulatory environments - including utility franchise agreements - might impose on specific business types could, instead of outright proscription, make it more expensive for developers to pursue a certain ownership type. Although the utility $100 \%$ ownership model is feasible in New York, it requires permission from the regulators, which increases the permitting costs of development. Similarly, a user $100 \%$ microgrid that crosses a public right of way could be allowed to operate if the user becomes a regulated utility, triggering a much higher level of responsibility and regulation. In this case, the regulatory environment is not proscribing the user $100 \%$, but it is making it significantly more expensive.

Ultimately, the feasibility of a microgrid or NMG system depends not only on the combination of proposed or desired ownership type and the local regulatory environment but also on the specific design of the microgrid and the services the microgrid provides in exchange for revenue. New York University received a waiver from New York City to operate a microgrid that crossed a public right of way. As mentioned, the need for a waiver might increase costs; however, the design of this microgrid was also an important factor. The waiver would not have been necessary if the university's microgrid had been designed not to cross public rights of way. This shows that the feasibility of the user $100 \%$ ownership model — or any other model, for that matter — does not solely depend on the local regulatory environment. In summary, the technical and economic feasibility of an NMG depends on the intersection of the regulatory environment, the ownership type, and the design of the microgrid. 


\section{Conclusions and Future Work}

The regulatory environment in which NMGs operate has a significant influence on the economic feasibility and spectrum of business model options available for microgrids. This report seeks to analyze how different regulatory environments enable and limit the design and operational boundaries of NMG systems in the United States. To this end, it provides information on the key attributes of different regulatory environments - including a regulatory environment ideal for the operation of NMGs - and possible ownership models that can be used to appropriately structure the OD\&O tool to design and assess the benefits of NMGs.

The three regulatory environments based on existing regulations and franchise agreementstraditional, partially deregulated, and deregulated - are not particularly conducive to operating an NMG system; however, under certain circumstances - including special waivers from public utility commissions or network designs that do not cross any public right of way — this could still be possible. In addition, regulatory reforms could result in changes sufficient to allow for networking microgrids in more environments. The NMG-friendly regulatory environment will allow operation of NMGs of all ownership types.

Future versions of the OD\&O tool are expected to include economic considerations in the design portion of the tool which makes expansion planning decisions. The economic calculations would include capital cost allocation, revenue allocation, consumption charges, and net present value (NPV) and these would depend on the ownership models. For example, in the case of capital investment allocation, network investments would have to be allocated to the utility in the unbundled case and to the users in the users $100 \%$ ownership cases, and DER investments would be allocated to the users for both these ownership models. A further example is that for the utility $100 \%$ ownership model, the utility revenue will be tariffs paid by users, and for the mixed ownership model, it will be tariffs paid by users and wheeling charges from energy exchanges between microgrids.

The operations portion of the tool is expected to be affected by the regulatory environment and ownership models as well in determining responsibility allocation for operational decisions such as generation dispatch, storage scheduling, and line switching. Ownership models influence, for example, generator dispatch and line switching that could be performed by the utility in the utility $100 \%$, mixed and unbundled ownership cases, and by the user in the users $100 \%$ case.

A more complete understanding of the impact of regulatory environments and ownership models on the benefits of networked microgrid systems could be achieved by generating a set of use cases that include a set of NMGs using one of the ownership models described in Section 3.1 and operating in one of the regulatory environments described in Section 2.4. The business model of each use case would result from the intersection between the enabling aspects and regulatory constraints of a given jurisdiction and the technical capabilities of the microgrid. Business models for use cases are represented by the yellow area in Figure 8. 


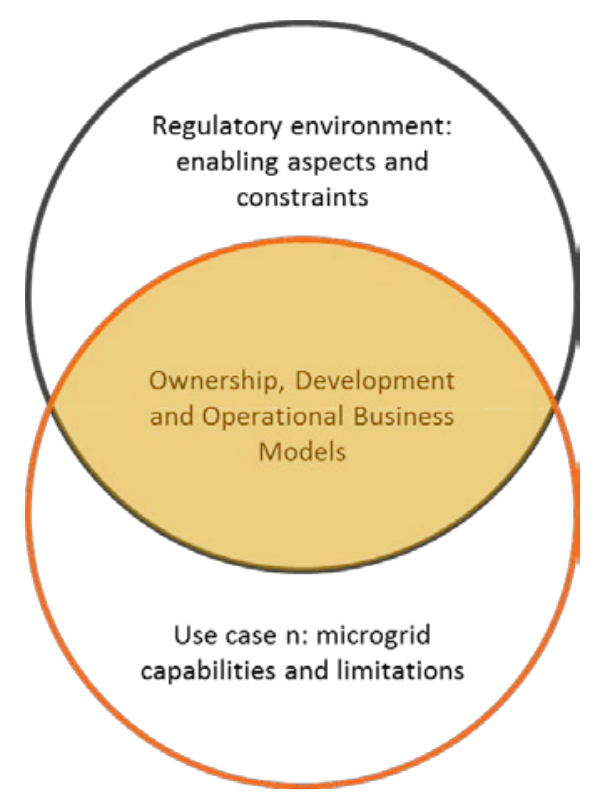

Figure 3. Business models are the result of the intersection between the enabling aspects and constraints of the regulatory environment and the capabilities of the microgrid.

The use cases should detail the value that each of the different potential attributes takes for each specific use case. For example, Table 1 describes the attributes of the system proposed by the City of Syracuse for the NY Prize (City of Syracuse 2016). Business models should be developed for each use case, including operation in grid-connected and islanded modes.

Table 1. System Attributes for the Proposed City of Syracuse Microgrid

\begin{tabular}{|l|l|l|l|}
\hline Concept/Variable & \multicolumn{2}{|l|}{ Possible Values } \\
\hline Regulatory environment & Traditional & $\begin{array}{l}\text { Partially } \\
\text { deregulated }\end{array}$ & Deregulated \\
\hline Who owns DERs & Utility & Users & \\
\hline $\begin{array}{l}\text { Who owns the microgrid's } \\
\text { network }\end{array}$ & Utility & Users & \\
\hline Ownership model & Utility $100 \%$ & Mixed & Unbundled \\
\hline Capital expenditure allocation & Decoupled & Co-op & N/A \\
\hline Operational transaction mode & Contract & Market & \\
\hline
\end{tabular}




\section{References}

Argonne National Laboratory, Reilly Associates, and Electric Power Research Institute. 2017. Integrated Distribution Management Systems. Lemont, IL. https://www.anl.gov/energysystems/publication/integrated-distribution-management-systems.

Backhaus, Scott N., Larisa Dobriansky, Steve Glover, Chen-Ching Liu, Patrick Looney, Salman Mashayekh, Annabelle Pratt, Keven Schneider, Michael Stadler, Michael Starke, Jianhui Wang, and Meng Yue. 2016. Networked Microgrids Scoping Study. Oak Ridge, TN: Oak Ridge National Laboratory. https://info.ornl.gov/sites/publications/Files/Pub68339.pdf.

Bade, Gavin. 2015. "Who Should Operate the Distribution Grid?" Utility Dive. https://www.utilitydive.com/news/who-should-operate-the-distribution-grid/376950/.

_ 2016. "New York PSC Enacts New Revenue Models for Utilities in REV Proceeding." Utility Dive. https://www.utilitydive.com/news/new-york-psc-enacts-new-revenue-models-forutilities-in-rev-proceeding/419596/.

Barnes, Arthur, Harsha Nagarajan, Emre Yamangil, Russell Bent, and Scott Backhaus. 2017. "Tools for Improving Resilience of Electric Distribution Systems with Networked Microgrids" (ArXiv:1705.08229 [Cs]), May. http://arxiv.org/abs/1705.08229.

Bialek, Thomas. 2014. Borrego Springs Microgrid Demonstration Project. Sacramento, CA: California Energy Commission. http://www.energy.ca.gov/2014publications/CEC-500-2014067/CEC-500-2014-067.pdf.

Bronin, Sara C., and Paul R. McCary. 2013. "Peaceful Coexistence. Independent Microgrids Are Coming. Will Franchised Utilities Fight Them or Foster Them?" Public Utilities Fortnightly. https://www.murthalaw.com/files/mccary_peaceful_coexistence_3 2013.pdf.

California Energy Commission, California Independent System Operator, and California Public Utilities Commission. 2017. Roadmap for Commercializing Microgrids in California.

Sacramento, CA. http://docketpublic.energy.ca.gov/PublicDocuments/16-EPIC01/TN221347_20170929T154043_Roadmap_for_Commercializing_Microgrids_in_California.p df.

California Public Utilities Commission. 2014. Microgrids: A Regulatory Perspective. San Francisco, CA. http://www.cpuc.ca.gov/WorkArea/DownloadAsset.aspx?id=5118.

Cardwell, Diane. 2017. "Solar Experiment Lets Neighbors Trade Energy Among Themselves." The New York Times, March 13, 2017, sec. Energy and Environment.

https://www.nytimes.com/2017/03/13/business/energy-environment/brooklyn-solar-grid-energytrading.html.

City of Syracuse. 2016. Syracuse Community Microgrid NY Prize Stage 1 Report. Syracuse, NY. https://www.nyserda.ny.gov/-/media/NYPrize/files/studies/74-City-of-Syracuse.pdf. 
COGEN Power Technologies. n.d. "Burrstone Energy Center." Accessed December 7, 2017. http://www.powerbycogen.com/burrstone-energy-center.

Community Microgrids Planning Academy. 2020. “About - NJ MicroGrids.” 2020.

https://www.microgrids.io/about/.

Connecticut Department of Energy and Environmental Protection. 2018. "DEEP: Connecticut Legislation \& Executive Orders on Climate."

http:/www.ct.gov/deep/cwp/view.asp?a=4423\&q=530290.

Deign, Jason. 2019. "Peer-to-Peer Energy Trading Still Looks Like a Distant Prospect." GreenTech Media. December 23, 2019. https://www.greentechmedia.com/articles/read/peer-topeer-energy-trading-still-looks-like-distant-prospect.

Eisenstat, Larry F., Richard Lehfeldt, and Diana Jeschke. 2016. "Microgrids: A Growing Trend In Search Of A Regulatory Model." Electric Light and Power Newsletter.

http://www.elp.com/Electric-Light-Power-Newsletter/articles/2016/05/microgrids-a-growingtrend-in-search-of-a-regulatory-model.html.

Electric Power Research Institute and Smart Electric Power Alliance. 2016. "Microgrids, Expanding Applications, Implementations, and Business Structures.” https://sepapower.org/.

Erickson, J. David. 2016. "Microgrids: A Regulatory Perspective.” Paper presented at the Joint Energy Agency Workshop to Kick Off the Development of a Roadmap to Commercialize Microgrids in California, May 24, 2016. http://www.energy.ca.gov/research/notices/2016-0524 workshop/presentations/David_Erickson_CPUC_Microgrids.pdf.

Girouard, Coley. 2017. "Should Utilities Be Allowed to Own Distributed Energy Resources?" Advanced Energy Economy. 2017. https://blog.aee.net/should-utilities-be-allowed-to-owndistributed-energy-resources.

Grimley, Matt, and John Farrell. 2016. Mighty Microgrids. Washington, D.C.: Institute for Local Self-Reliance. https://ilsr.org/wp-content/uploads/downloads/2016/03/Report-MightyMicrogrids-PDF-3_3 16.pdf.

Hansen, Lee R. 2012. "Microgrids.” Paper prepared for the Connecticut General Assembly Office of Legislative Research. https:/www.cga.ct.gov/2012/rpt/2012-R-0417.htm.

Harvard Business Review Analytic Services. 2017. "Business Resiliency and Energy Innovation." Harvard Business Review. https://hbr.org/sponsored/2017/09/business-resiliencyand-energy-innovation.

Joos, Geza, Jim Reilly, Ward Bower, and Russ Neal. 2017. "The Need for Standardization: The Benefits to the Core Functions of the Microgrid Control System." IEEE Power and Energy Magazine 15, no. 4: 32-40. 
KEMA and Massachusetts Clean Energy Center. 2014. Microgrids: Benefits, Models, Barriers and Suggested Policy Initiatives for the Commonwealth of Massachusetts. Burlington, MA. http://files.masscec.com/research/Microgrids.pdf.

Lawrence Berkeley National Laboratory. n.d. "Santa Rita Jail.” Accessed December 7, 2017. https://building-microgrid.lbl.gov/santa-rita-jail.

Lott, Melissa C. 2015. "Peer-to-Peer Energy Trading Dreams of Being 'Bigger Than E.ON." Scientific American Blog Network. https://blogs.scientificamerican.com/plugged-in/peer-to-peerenergy-trading-dreams-of-being-bigger-than-e-on/.

Madathil, S.C., E. Yamangil, H. Nagarajan, A. Barnes, R. Bent, S. Backhaus, S.J. Mason, S. Mashayekh, and M. Stadler. 2017. "Resilient Off-Grid Microgrids: Capacity Planning and N-1 Security." IEEE Transactions on Smart Grid PP, no. 99: 1-1. https://doi.org/10.1109/TSG.2017.2715074.

Mengelkamp, Esther, Johannes Gärttner, Kerstin Rock, Scott Kessler, Lawrence Orsini, and Christof Weinhardt. 2017. "Designing Microgrid Energy Markets: A Case Study: The Brooklyn Microgrid.” Applied Energy (June). https://doi.org/10.1016/j.apenergy.2017.06.054.

Nagarajan, Harsha, Hassan Hizaji, Russell Bent, and Scott Backhaus. Forthcoming. Optimal Design and Operation of Networked Microgrids: Mathematical Framework. Los Alamos, NM: Los Alamos National Laboratory.

National Electrical Manufacturers Association. 2018. State Regulatory and Policy Considerations for Increased Microgrid Deployment. Rosslyn, VA.

New Jersey Board of Public Utilities. 2016. Microgrid Report. Trenton, NJ. https://www.nj.gov/bpu/pdf/reports/20161130_microgrid_report.pdf.

New York State Energy Research and Development Authority. 2010. Microgrids: An Assessment of the Value, Opportunities and Barriers to Deployment in New York State. New York, NY. https://www.nyserda.ny.gov/-/media/Files/Publications/Research/Electic-PowerDelivery/microgrids-value-opportunities-barriers.pdf.

—. 2020. "Competition Structure.” https://www.nyserda.ny.gov/AllPrograms/Programs/NY-Prize/Competition-Structure.

New York State. n.d. "Reforming the Energy Vision.” Accessed January 11, 2018. https://rev.ny.gov/.

Pacific Gas and Electric. n.d. "Community Choice Aggregation.” Accessed December 4, 2017. https://www.pge.com/en_US/residential/customer-service/other-services/alternative-energyproviders/community-choice-aggregation/community-choice-aggregation.page. 
Pennsylvania General Assembly. 2018. "Bill Information - House Bill 1412; Regular Session 2017-2018."

https://www.legis.state.pa.us/cfdocs/billInfo/billInfo.cfm?sYear=2017\&sInd=0\&body=H\&type= $\underline{\mathrm{B} \& b n=1412}$

Proudlove, Autumn, Brian Lips, and David Sarkisian. 2019. 50 States of Grid Modernization, Q1 2019 Quarterly Report. Raleigh, NC: North Carolina Clean Energy Technology Center.

Proudlove, Autumn, Brian Lips, David Sarkisian, and Achyut Shrestha. 2019. 50 States of Grid Modernization, Q4 2018 Quarterly Report \& 2018 Annual Review. Raleigh, NC: North Carolina Clean Energy Technology Center.

Pyper, Julia. 2015. "Oncor, S\&C, and Schneider Electric Complete a Unique Four-Part Microgrid." GreenTech Media. April 7, 2015. https://www.greentechmedia.com/articles/read/oncor-sc-and-schneider-electric-complete-theirinnovative-four-part-microgr.

2016. "Utilities See Distributed Generation as a Challenge—and Owning It as the Solution." GreenTech Media. February 18, 2016.

https://www.greentechmedia.com/articles/read/utilities-see-distributed-generation-as-achallenge-and-owning-it-as-the-so.

Saadeh, Omar. 2015. "Microgrids Flourishing in Spite of Regulatory Barriers." GreenTech Media. August 27, 2015. https://www.greentechmedia.com/articles/read/microgrids-flourishingin-spite-of-regulatory-barriers.

Schneider Electric. 2016. Oncor Microgrid Case Study. 2016. https://www.schneiderelectric.us/en/download/document/3070AC1503/.

Siemens. 2015. Microgrid Start Up: A Guide to Navigating the Financial, Regulatory, and Technical Challenges of Microgrid Implementation.

http://w3.usa.siemens.com/smartgrid/us/en/microgrid/documents/ebook.pdf.

Utility Dive. 2014. The Utility View of Microgrids.

http://app.assetdl.com/landingpage/microgrid-2014/.

Spector, Julian. 2017. "Microgrids on the March: Utilities Are Building Out New Business Models to Make Islanding Work." GreenTech Media. February 7, 2017.

https://www.greentechmedia.com/articles/read/distributech-roundup-microgrids-on-the-march.

Stanton, Tom, and Michael J Zimmer. 2018. POLICY PATHWAYS FOR MICROGRIDSProgress Cases from Multiple Jurisdictions. Columbus, OH: National Regulatory Research Institute; and Alexandra, VA: Microgrid Institute.

https://www.districtenergy.org/HigherLogic/System/DownloadDocumentFile.ashx?DocumentFil eKey=af51a260-c115-84aa-0778-1efd304dc6de\& forceDialog $=0$. 
St. John, Jeff. 2018. "Illinois Decision Opens the Path to Shared Utility-Customer Microgrids." GreenTech Media. https://www.greentechmedia.com/articles/read/illinois-decision-opens-thepath-to-shared-utility-customer-microgrids.

Stein, Eric. 2017. Personal communications.

Ton, Dan T., and Merrill A. Smith. 2012. “The U.S. Department of Energy's Microgrid Initiative." The Electricity Journal.

https://energy.gov/sites/prod/files/2016/06/f32/The\%20US\%20Department\%20of\%20Energy $\% 2$

7s\%20Microgrid\%20Initiative.pdf.

U.S. Department of Energy. 2017. Transforming the Nation's Electricity System. Quadrennial Energy Review: Second Installment. Washington, D.C.

https://energy.gov/policy/initiatives/quadrennial-energy-review-qer/quadrennial-energy-reviewsecond-installment.

Walsh, Conor. 2014. "Microgrid Regulatory Policy in the U.S." CivicSolar.

https://www.civicsolar.com/support/installer/articles/microgrid-regulatory-policy-us.

Walton, Robert. 2017. "Pennsylvania Bill Would Allow Utilities to Earn Returns on Microgrids, Storage." Utility Dive. https://www.utilitydive.com/news/pennsylvania-bill-would-allowutilities-to-earn-returns-on-microgrids-stor/443813/.

Wang, Jianhui, Chen Chen, and Xiaonan Lu. 2015. Guidelines for Implementing Advanced Distribution Management Systems-Requirements for DMS Integration with DERMS and Microgrids (ANL/ESD-15/15). Lemont, IL: Argonne National Laboratory. https://doi.org/10.2172/1212266.

Wood, Elisa. 2017a. "Community Microgrids in New Jersey Receiving High Touch Treatment." Microgrid Knowledge (blog), August 22, 2017. https://microgridknowledge.com/communitymicrogrids-new-jersey/.

Wood, Elisa. 2017b. "Hearing Monday, June 19 on Pennsylvania Microgrid Bill.” Microgrid Knowledge (blog), June 18, 2017. https://microgridknowledge.com/pennsylvania-microgrid-bill/.

Wood, Eliza. 2018. "Special Alert: ComEd Wins Approval for Innovative Microgrid Cluster in Chicago" Microgrid Knowledge (blog), March 6, 2018.

https://microgridknowledge.com/microgrid-cluster-chicago-approved/. 